\title{
Fibroma of the orbit
}

\author{
ALY MORTADA \\ Department of Ophthalmology, Faculty of Medicine, Cairo University, Egypt
}

Orbital fibromata are very rare according to Duke-Elder (1952). Among 877 orbital tumours, Reese (1963) reported only three fibromata.

\section{Case reports}

In the two following cases the general condition of the patients was good. The total and $\mathcal{G H}^{\dot{N}}$ differential blood counts were normal; the blood Wassermann reaction and the tuberculin ${ }_{\circ}$ test were negative. There was no history of trauma, and the proptosis was painless and slow to develop.

Case I, a 25-year-old male (Fig. I), had a left proptosis which had developed slowly during the past $\vec{\varphi}$ 3 years. The right eye was normal, and the visual acuity $6 / 6$.

The left eye showed conjunctival chemosis, inward proptosis of $26 \mathrm{~mm}$. (Hertel), and limitation of ocular movements downwards and outwards. The visual acuity was 6/12. The fundus showed engorgement of the retinal vessels. A hard mass was felt between the eye and the outer lower orbital margin.

Skull $x$ rays showed no abnormality of the orbital bones.

The mass, which was removed through an anterior orbitotomy, measured $3 \times 2 \times 1 \mathrm{~cm}$. It was encapsulated, hard, and adherent to the periorbita of the lower outer orbital wall.

HISTOPATHOLOGICAL EXAMINATION

There were fibrocytes in a fibrous stroma (Fig. 2).

RESULT

There was no recurrence after 5 years' follow-up (Fig. 3).

Case 2, a 6-year-old boy (Fig. 4), had a slowly developing left proptosis of 4 years' duration. The right eye was normal, with visual acuity $6 / 9$.

The left eye showed downward proptosis of $24 \mathrm{~mm}$. (Hertel) and limitation of ocular movement $\mathcal{O}^{\circ}$ upwards. The visual acuity was $6 / 9$ and the fundus normal. A hard mass was felt between then eye and the upper orbital margin.

Skull $x$ rays (postero-anterior view) showed a dilated left orbit.

The tumour when removed was found to be hard and encapsulated. It measured $2 \times 2 \times 1 \mathrm{~cm}$., and was adherent to the periosteum of the upper orbital wall.

histopathological examination. The tumour was an orbital fibroma (Fig. 5).

RESULT

There was no recurrence after 5 years' follow-up. 


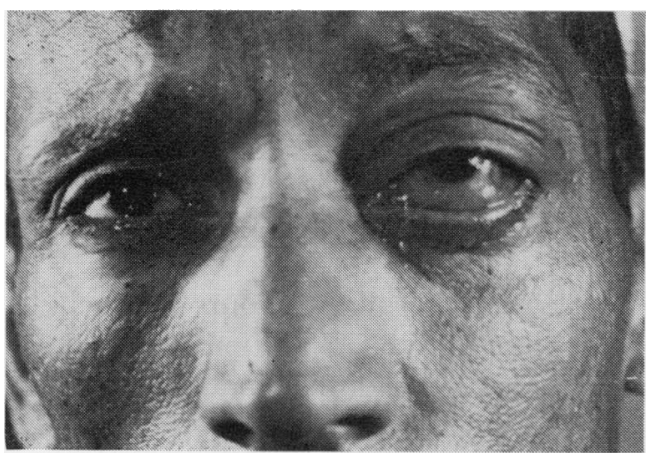

FIG. I Case I. Left proptosis of 3 years' duration in a male aged 25 years. This was due to a flat orbital fibroma adherent to the periosteum of the inferolateral orbital wall

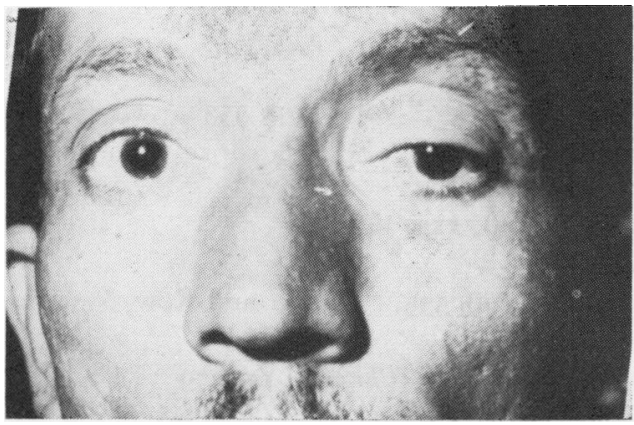

F1G. 3 Case I. Patient's appearance 5 years after removal of orbital fibroma

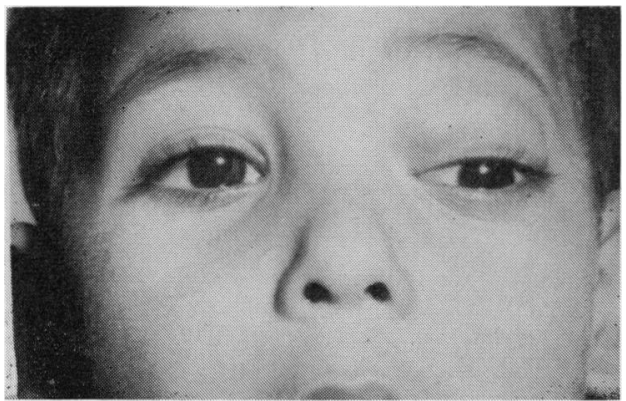

F I G. 4 Case 2. Left proptosis of I year's duration in a boy aged 6 years

FIG. 5 Case 2. Orbital fibroma. $\times 120$

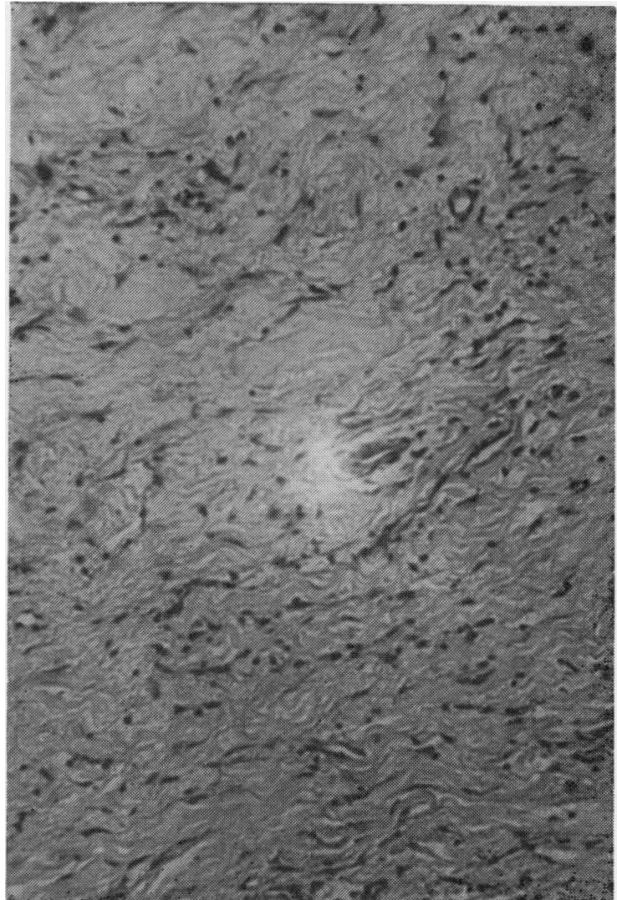

FIG. 2 Case I. Orbital fibroma. $\times 120$

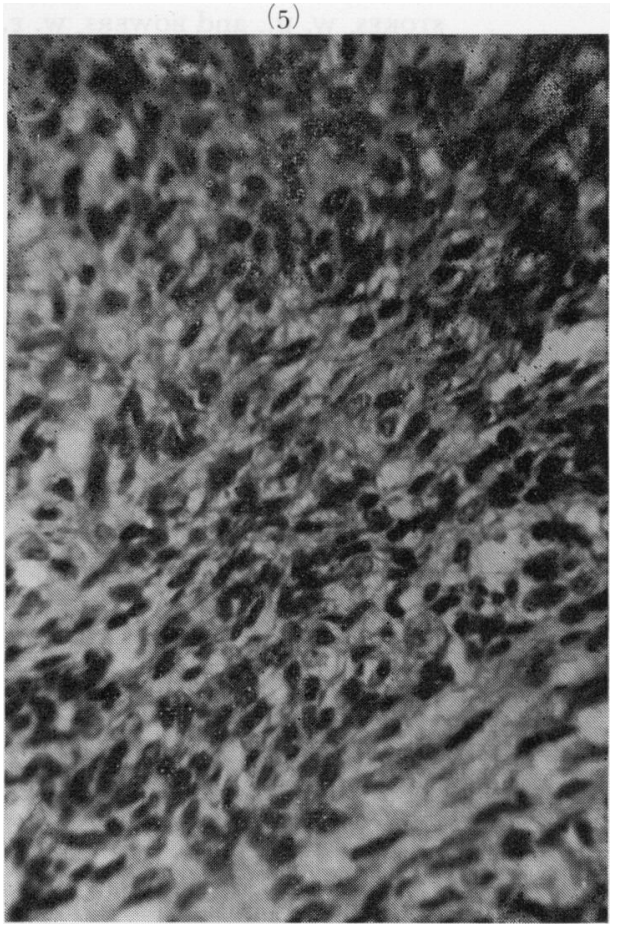




\section{Discussion}

Fibromata of the orbit usually arise from the upper part of the periorbita (Stokes and Bowers, I934; Garcia Miranda, 1947). They may also arise in the muscle cone (Fowler and Terplan, I942) attached to the sheath of one of the rectus muscles (Reese, I94I) or of the optic nerve (Forrest, I949). They usually appear before the age of 16 years and rarely after the age of 30 years.

My series of 900 histopathologically diagnosed orbital tumours has included only these two cases of orbital fibroma. Histopathologically this condition has to be differentiated from fibrosing haemangioma, fibrosing haemangio-endothelioma, and fibrosis in a pseudotumour.

\section{Summary}

(I) Two very rare cases of orbital fibromata are described.

(2) In both cases the tumour occurred in relation to the periosteum of the orbital bones. (3) The patients' ages were 6 and 25 years.

\section{References}

DUKe-ELder, s. (1952) “Text-book of Ophthalmology," vol. 5, pp. 5532. Kimpton, London FORRest, A. W. (1949) Arch. Ophthal. (Chicago), 41, I98

FOWLER, J. G., and TERPLAN, K. L. (1942) Ibid., 28, 263

GARCIA MIRANDA, A. (1947) Ophthalmologica (Basel), II3, I49

REESE, A. B. (1941) Amer. F. Ophthal. 24, 386

___ (1963) “Tumors of the Eye", 2nd ed., pp. 535. Harper and Row, New York, Evanston, and London

stokes, w. H., and вowers, w. F. (1934) Arch. Ophthal. (Chicago), ir, 279 